\title{
Incidence and Predictors of Tuberculosis among HIV/AIDS Infected Patients: A Five-Year Retrospective Follow-Up Study
}

\author{
Mulugeta Dalbo1, Alemu Tamiso ${ }^{2 *}$ \\ ${ }^{1}$ Department of Public Health Nursing, Arba Minch Health Science College, Arba Minch, Ethiopia \\ ${ }^{2}$ Unit of Epidemiology and Biostatistics, Department of Public Health, College of Medicine and Health Sciences, \\ Arba Minch University, Arba Minch, Ethiopia \\ Email: mulugetadalbo@gmail.com, tamisodebiso@gmail.com
}

Received 24 February 2016; accepted 19 June 2016; published 22 June 2016

Copyright (C) 2016 by authors and Scientific Research Publishing Inc.

This work is licensed under the Creative Commons Attribution International License (CC BY). http://creativecommons.org/licenses/by/4.0/

(c) (i) Open Access

\section{Abstract}

Background: Despite increased deliverance of antiretroviral therapy (ART), morbidity and mortality from TB are still predominant among HIV/AIDS infected patients in Ethiopia. Thus, current study aimed to determine magnitude and predictors of tuberculosis among cohort of HIV infected patients at Arba Minch General Hospital, Ethiopia, 2015. Methods: Hospital based retrospective follow-up study was conducted among study population which was HIV/AIDS infected individuals registered from September 2007 to 2013 . The data were collected using structured data abstraction form and four ART trained nurses were used to abstract the data. The data were checked for completeness, cleaned and entered into Epi Info 7.0 and analyzed using SPSS version (IBM-21). Results were summarized by using table of frequency, graph, and measure of central tendency. Statistical significance was inferred at $P$-value $\leq 0.05$. Adjusted odd ratio (AOR) with $95 \%$ confidence interval (CI) was used to determine predictors. Result: Four hundred ninety six patient's charts were abstracted. Cumulative and incidence density of tuberculosis were $21.4 \%$ (95\% CI: $21.3,21.44$ ) and 5.36 per 100 person year respectively. Cigarette smokers (AOR: $2.82,95 \% \mathrm{CI}$ (1.27 - 6.27)), household with family size of 3 - 4 (AOR: 2.26, 95\% CI (1.14 - 4.50)), baseline WHO clinical stage III (AOR: 20.26, 95\% CI (7.09 - 57.6)) and IV (AOR: 22.9, 95\% CI (6.91 - 76.4)) and heamoglobin level of <10 (AOR: 2.56 , 95\% CI (1.22 - 5.33)) were important predictors (risk factors) of tuberculosis among HIV infected patients. Conclusion and recommendation: Relatively high incident tuberculosis cases were established among HIV infected patients and history of cigarette smoking; family size; hemoglobin level and base line WHO clinical stage were responsible for this incidence. Therefore; early initiation of HAART as per current guideline should get stressed, and the finding that smoking was important predictors for TB in Ethiopia had obvious TB control implication which required high attention focused on fighting against cigarette smoking among HIV infected cohort.

${ }^{*}$ Corresponding author. 


\section{Keywords}

\section{Tuberculosis, HIV Infection, Incidence, Predictors, Arba Minch General Hospital, Ethiopia}

\section{Introduction}

Tuberculosis (TB) remains one of the world's deadliest communicable diseases. In 2013, an estimated 9.0 million people developed TB and 1.5 million died from the disease [1]. An estimated 1.1 million (13\%) of the 9 million people who developed TB in 2013 were HIV-positive. The African Region accounts for about four out of every five HIV-positive TB cases and TB deaths among people who are HIV positive and the majority of victim live in sub Saharan Africa, which accounts seventy percent (70\%) [1] [2]. Some Africa countries have reported continuing rises in tuberculosis case rates despite declining HIV prevalence, while others show stable or declining tuberculosis incidence among HIV-negative individuals [3].

Tuberculosis has been recognized as a major public health problem for more than five decades in Ethiopia. Ethiopia is one of the 22 high burden countries (HBCs) and TB remains one of the leading causes of mortality. According to the 2014 WHO report, the prevalence and incidence of all forms of TB are 211 and 224 per 100,000 of the population, respectively. About $13 \%$ of all new TB cases are also HIV co-infected. Moreover, Ethiopia is one of the high TB/HIV and multidrug resistant TB (MDR TB) burden countries. Among TB patients with known HIV status, about $11 \%$ were HIV co-infected. [1] [4]

Despite increased deliverance of antiretroviral therapy (ART), morbidity and mortality from TB are still predominant among PLHIV. Among 33.2 million individuals acquiring human immune deficiency virus (HIV), one-third of them are concomitantly infected with Mycobacterium tuberculosis [5].

The TB/HIV co-infection results derangement of quality of life, poor physical health than HIV infected individuals and has a greater risk of common mental disorders [6] [7].

Moreover, the management of a TB and HIV co-infected individual is challenging because of frequent oral drug intake which can cause different problem [8], increased drug adverse effects [9], drug and drug interaction [10] and the immune reconstitution inflammatory syndrome (IRIS) [11].

The risk of tuberculosis among PLHIV is 20 times higher than HIV negative people [2] [12] [13], and baseline CD4+ lymphocyte count, history of injectable drug use, antiretroviral therapy, body mass index, anemia, and educational status were some of the contributing factors for TB in HIV patients [14] [15].

Many efforts have been made to integrate TB diagnosis and treatment with HIV care in order to prevent, diagnose and manage TB among HIV infected individuals, though TB still occur in HIV patients who are on HAART receiving individuals [1] [16]. Therefore; there should be early screening and detection of TB in PLHIV as TB can occur in any course of HIV treatment [17] [18].

Furthermore, adequate understanding of the specific situation through follow-up research should be done to provide baseline finding to program designing for respective organization. Therefore, this study aimed to determine the incidence and predictors of TB among PLHIV registered at Arba Minch General Hospital.

\section{Methodology}

\subsection{Study Settings and Period}

This study was conducted at the government owned General Hospital located in Arba Minch town, Southern Ethiopia. The town is $500 \mathrm{~km}$ south of Addis Ababa. In the hospital all HIV positive people from any service area were enrolled in ART clinic for comprehensive HIV care. There are multidisciplinary professional's team that includes physicians, nurses, public health professionals, laboratory technologists, pharmacists, data clerks and volunteer adherence supporters. ART is being provided for HIV infected adult patients according to CD4 count and WHO clinical stage.

\subsection{Study Design and Period}

Hospital based retrospective follow up study was employed from December 2014-January 2015. 


\subsection{Source and Study Population}

All HIV infected patients attending ART clinic of Arba Minch General Hospital and HIV infected individuals registered between September 2007 and August 2013 were source and study population respectively.

Inclusion criteria: All PLHIV aged 15 years and above and were enrolled into the adult chronic HIV care at the Arba Minch general Hospital were included in the study

Exclusion criteria: An individual with incomplete chart and diagnosed clinically without sputum examination, culture and chest $\mathrm{X}$-ray were excluded from the study.

\subsection{Sample Size Determination}

Sample size was determined for first specific objective by using StatCalc program of Epi Info, with the assumption of Z-score corresponding to 95\% confidence interval, 28.9\% proportion of tuberculosis among HIV positive patients, $4 \%$ degree of precision, ten percent of non-response rate and total enrolled patients (6015) in Arba Minch general hospital which resulted $\mathbf{5 0 2}$ samples.

Sample size was also calculated for second specific objective from the study conducted in Gondar University hospital and Felege-Hiwot Referral Hospital [13] [19]. Thus, Sample size calculated for the second specific objectives; CD4 count ( $>200$ ) by considering $10 \%$ of lost to follow up, resulted 436 , which is less than sample size calculated for first specific objective, so sample size (502) calculated for first specific objective was taken as sample size (Table 1).

\subsection{Sampling Procedure}

Simple random sampling was used through randomly generated number from patient's data of 2007-2013. Despite, charts were organized on the shelf according to the hospital card number, which is given in chronological (sequential) order. Some of charts in the hospital were not arranged in numerical order, so new numbering started from 1 up to 2000 were assigned to charts of two thousand patients registered between 2007 and 2013. After a number was assigned to each chart, investigator draw 502 sample charts and among them 496 that fulfilled the inclusion criteria was reviewed one by one and the information was transcribed to the pre-structured data abstraction form.

\subsection{Data Collection Procedures}

Structured data abstraction form was prepared and used for chart review. Four ART nurses abstracted the data from ART registry book of HIV infected patients who had follow up starting from 2007 up to 2013 under supervision of medical doctors who were got trained for this purpose. Principal investigator rechecked if there is incomplete and inconsistent abstraction from the chart at every day, if incomplete checklist was found, he sent back to data collectors for correction.

\subsection{Operational Definitions}

Incident TB case: which was defined in this study, as an event, diagnosed with Sputum smear (+) (at least two), chest X-ray (suggestive of TB finding) and culture positive during follow-up, which was ascertained retrospectively?

Cumulative Incidence of TB: It was calculated by dividing total new occurrence of Tuberculosis to all total sampled patients.

Table 1. Sample size calculated for second specific objectives, 2015.

\begin{tabular}{cccccccc}
\hline Variables & CI & Power & OR & Ratio & Percent in unexposed & Lost to follow up & Sample size \\
\hline Functional status/Working group & $95 \%$ & $90 \%$ & 2.67 & 1 & $23.1 \%$ & $10 \%$ & 242 \\
WHO stage IV/Stage I/II & $95 \%$ & $90 \%$ & 10.3 & 1 & $10.4 \%$ & $10 \%$ & 57 \\
CD4 count >200 & $95 \%$ & $90 \%$ & 2.13 & 1 & $21 \%$ & $10 \%$ & 396 \\
Body mass index & $95 \%$ & $90 \%$ & 8.2 & & $3.8 \%$ & $10 \%$ & 127 \\
\hline
\end{tabular}


Incidence rate of Tuberculosis: Incidence rate in this research was calculated by dividing all new occurrence of Tuberculosis to total follow up time of patients in year.

TB diagnosis: TB was diagnosed using microscopic examinations of sputum smears, chest radiology, fineneedle aspiration of lymph-adenopathy, cytology with very high clinical grounds and mycobacterium culture.

\subsection{Data Management and Analysis}

Data was coded manually, entered and cleaned using Epi-Info 7 and exported to SPSS version 21 for descriptive and inferential analyses. Frequencies and cross tabulations were used to check for missed values and variables. Data was presented by using frequency, tables, and summarized by using mean and standard deviation. Back ward Logistic regression analysis was conducted to see the effect of explanatory variables on TB incidence and Statistical significance was inferred at P-value $<0.05$. Adjusted odd ratios with $95 \%$ confidence interval (CI) were used to determine predictors.

\subsection{Ethical Consideration}

The study was approved by the institutional review board of Addis continental institute of Public health which was coordinated by Arba Minch University/CMHS. Additional written permission to conduct the study on medical records of patients was obtained from the Arba Minch General hospital. Personal identifiers were excluded during data abstraction. Since it is secondary data obtaining informed consents from the participants was not possible, but the confidentiality of information was maintained by not recording their name from the chart and keeping the data anonymous.

\section{Result}

\subsection{Socio-Demographic and Economic Characteristics}

Four hundred ninety six records of HIV Infected patients were analyzed. Their mean age was 33.8 ( \pm 8.89 SD) years and almost half, 235 (47.4\%), of them were in the age group of 25 - 34 years. Over half (58.1\%) of the PLHIV were females and the majority (73.4\%), of them were urban dwellers.

Almost all (99.8\%) patients disclosed their HIV status, to their brothers/sisters/parents. Forty three (8.7\%) of them were cigarette smokers (see Table 2).

\subsection{Base Line Clinical Characteristics}

One hundred seventeen nine (36.1\%) of them were at WHO clinical stage 3 during enrolment. Three hundred twenty five (65.2\%) of the participants were on working status at baseline. The median CD4 count during enrollment was 221 (IQR: 125 - 340.7).

The predominant regimens initially prescribed were a combination of (TDF + 3TC + NBC) and (3TC + EFV + NVP) (38.3\%), followed by Staudinger, Lamivudine and, Nevirapine (17.8\%).

One hundred thirteen (22.8\%) patients had changed their initial regimen during the follow up period mainly to $(\mathrm{TDF}+3 \mathrm{TC}+\mathrm{NVP})+(3 \mathrm{TC}+\mathrm{EFV}+\mathrm{NVP}) 45$ (9.6\%), and ten (8.85\%) patients were switched to second line HAART.

For 105 (92.9\%) and 3 (2.65\%) patients, regimens were changed due to drug side effect and TB occurrence respectively, while the reasons for changing the initial regimen were not recorded for 4 (3.54\%) patients (see Figure 1 and Figure 2, see Table 3).

\subsection{Incidence of TB in People Living with HIV/AIDS}

Cumulative incidence and incidence rate of tuberculosis among PLHIV patients was 21.4\% $(21.3,21.44)$ and 5.36 per 100 persons year respectively (see Figure 3).

\subsection{Bivariable Logistic Regression Analysis}

Bivariable logistic regression analysis of socio-demographic and Behavioral variables on incidence of TBC revealed that age, sex, disclosure of HIV status to one of family member, history of cigarette smoking and household family size were predictors of incidence of TB, but all other variable like educational status, marital status, 
Table 2. Socio-demographic characteristics of HIV Infected patients at Arba Minch General Hospital (2007 and 2013 G.C).

\begin{tabular}{|c|c|c|}
\hline Variable & Frequency & $(\%)$ \\
\hline \multicolumn{3}{|l|}{ Sex } \\
\hline $\begin{array}{c}\text { Male } \\
\text { Female }\end{array}$ & $\begin{array}{l}208 \\
288\end{array}$ & $\begin{array}{l}41.9 \\
58.1\end{array}$ \\
\hline \multicolumn{3}{|l|}{ Age $(33.2+8.89)$} \\
\hline $\begin{array}{c}15-24 \\
25-34 \\
35-44 \\
\geq 45\end{array}$ & $\begin{array}{c}66 \\
235 \\
137 \\
58\end{array}$ & $\begin{array}{l}13.3 \\
47.4 \\
27.6 \\
11.7\end{array}$ \\
\hline \multicolumn{3}{|l|}{ Marital status } \\
\hline $\begin{array}{l}\text { Married } \\
\text { Single } \\
\text { Divorced } \\
\text { Separated } \\
\text { Widowed }\end{array}$ & $\begin{array}{c}321 \\
60 \\
54 \\
29 \\
32\end{array}$ & $\begin{array}{c}64.7 \\
12.1 \\
10.9 \\
5.8 \\
6.5\end{array}$ \\
\hline \multicolumn{3}{|l|}{ Residence } \\
\hline $\begin{array}{l}\text { Urban } \\
\text { Rural }\end{array}$ & $\begin{array}{l}364 \\
132\end{array}$ & $\begin{array}{l}73.4 \\
26.6\end{array}$ \\
\hline \multicolumn{3}{|l|}{ Religion } \\
\hline $\begin{array}{l}\text { Orthodox } \\
\text { Muslim } \\
\text { Protestant }\end{array}$ & $\begin{array}{c}334 \\
21 \\
141\end{array}$ & $\begin{array}{c}67.3 \\
28.4 \\
4.2\end{array}$ \\
\hline \multicolumn{3}{|l|}{ Level of educational } \\
\hline $\begin{array}{c}\text { No education } \\
\text { Primary } \\
\text { Secondary } \\
\text { Tertiary }\end{array}$ & $\begin{array}{c}116 \\
169 \\
158 \\
53\end{array}$ & $\begin{array}{l}23.4 \\
34.1 \\
31.9 \\
10.7\end{array}$ \\
\hline \multicolumn{3}{|l|}{ Occupation } \\
\hline $\begin{array}{c}\text { Farmer } \\
\text { Government employ } \\
\text { Housewife } \\
\text { Merchant } \\
\text { Private gainful work } \\
\text { Others (unspecified job) }\end{array}$ & $\begin{array}{c}24 \\
72 \\
158 \\
44 \\
67 \\
131\end{array}$ & $\begin{array}{c}4.8 \\
14.5 \\
31.9 \\
8.9 \\
26.4 \\
13.5\end{array}$ \\
\hline \multicolumn{3}{|l|}{ Addiction } \\
\hline $\begin{array}{c}\text { Addicted } \\
\text { Not addicted }\end{array}$ & $\begin{array}{c}39 \\
457\end{array}$ & $\begin{array}{c}7.9 \\
92.1\end{array}$ \\
\hline \multicolumn{3}{|l|}{ Family size } \\
\hline $\begin{array}{c}\leq 2 \\
3-4 \\
\geq 5\end{array}$ & $\begin{array}{l}127 \\
221 \\
148\end{array}$ & $\begin{array}{l}25.6 \\
44.6 \\
29.8\end{array}$ \\
\hline \multicolumn{3}{|l|}{ Cigarette smoking } \\
\hline $\begin{array}{l}\text { Yes } \\
\text { No }\end{array}$ & $\begin{array}{c}43 \\
453\end{array}$ & $\begin{array}{c}8.7 \\
91.3\end{array}$ \\
\hline
\end{tabular}

and other analyzed were not predict Incidence of Tuberculosis among HIV infected patients (see Table 4).

\subsection{Factors Associated with TB Incidence in People Living with HIV (Multivariable Logistic Regression Analysis)}

In multivariable logistic regression analysis, Family size, History of cigarettes smoking, Baseline WHO clinical 


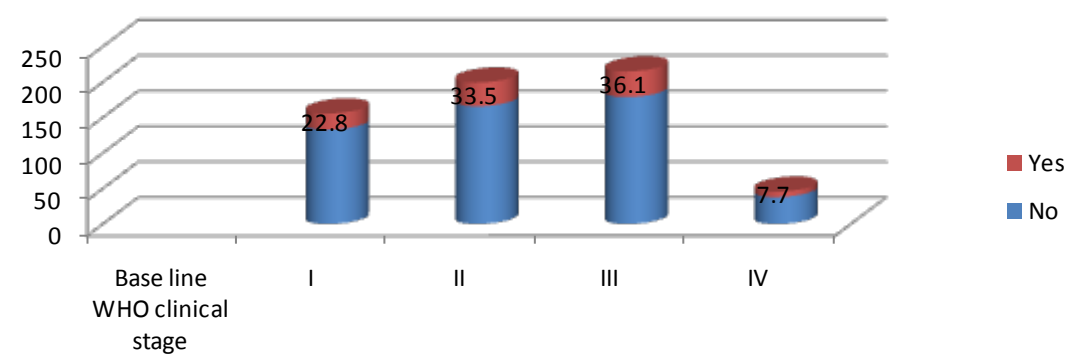

Figure 1. Baseline WHO clinical stage of HIV infected people at AGH, 2015.

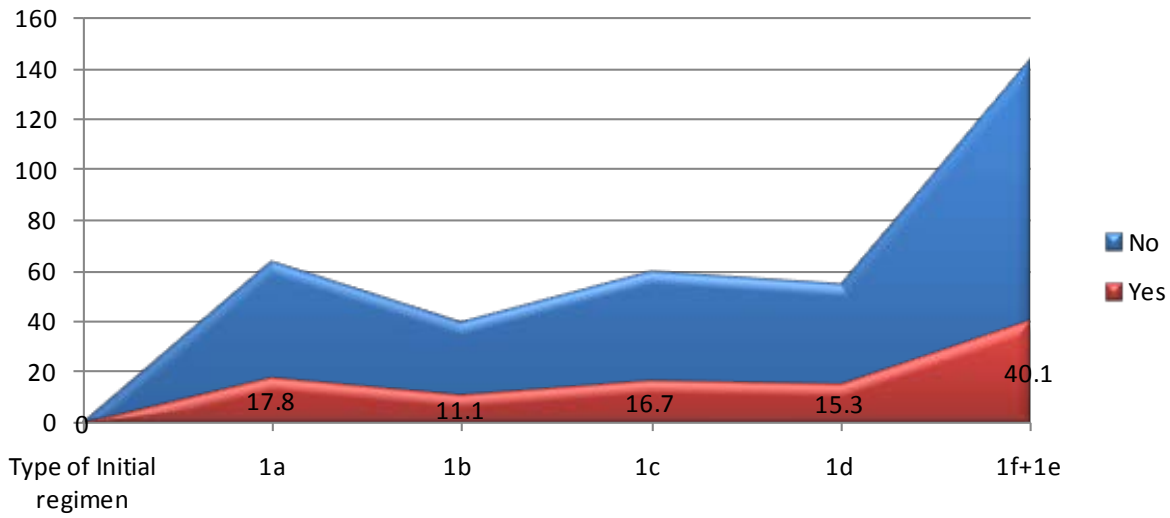

Figure 2. Anti retroviral intervention type for HIV infected patients at AGH, 2015.

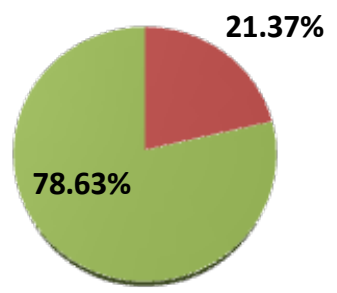

$$
\begin{aligned}
& \text { - Incidence of Tuberculosis } \\
& \text { - Yes } \\
& \text { - No }
\end{aligned}
$$

Figure 3. Cumulative incidence of tuberculosis among PLHIV patients, at AGH 2015.

Table 3. Clinical characteristics of HIV infected patients registered in Arba Minch General Hospital between 2007 and 2013.

\begin{tabular}{ccc}
\hline Variables & Frequency & $\%$ \\
\hline ART intervention & & \\
Pre-ART & 137 & 27.6 \\
HAART & 359 & 72.6 \\
Regimen change during follow up & & \\
Yes & 113 & 22.8 \\
No & 383 & 77.2 \\
New regimen & & \\
First line & 103 & 91.2 \\
$2^{\text {nd }}$ line & 10 & 8.85 \\
Side effect & & \\
Pregnancy & 105 & 92.9 \\
Tuberculosis & 1 & 0.88 \\
Others & 3 & 2.65 \\
Reason for switch first regimen & 4 & 3.54 \\
Past TB treatment history & & \\
Yes & 68 & 86.3 \\
No & 428 & \\
\hline
\end{tabular}




\section{Continued}

\begin{tabular}{ccc} 
Functional status & & \\
Working & $\mathbf{3 2 5}$ & $\mathbf{6 5 . 5}$ \\
Ambulatory & $\mathbf{1 3 4}$ & $\mathbf{2 7 . 0}$ \\
Bed redden & $\mathbf{3 7}$ & $\mathbf{7 . 5}$ \\
CD4 count & & \\
$<50$ & 35 & 7.1 \\
$50-100$ & 58 & 11.7 \\
$101-200$ & 127 & 25.6 \\
200 & 276 & 55.6 \\
Hemoglobin & & \\
$<10$ & 17 & 3.4 \\
$\geq 10$ & 479 & 96.6 \\
Year of follow up & & \\
$\leq 1$ & 16 & 3.2 \\
$1-3$ & 129 & 26.0 \\
$\geq 3$ & 351 & 70.8 \\
\hline
\end{tabular}

Table 4. Association between socio-demographic and behavioral characteristics with incidence of TB among HIV infected patients in Arba Minch General Hospital, 2015.

\begin{tabular}{|c|c|c|c|}
\hline \multirow{2}{*}{ Variable } & \multicolumn{2}{|c|}{ Incidence of tuberculosis } & \multirow{2}{*}{ COR (95\% CI) } \\
\hline & Yes (\%) & No (\%) & \\
\hline \multicolumn{4}{|l|}{ Age } \\
\hline $15-24$ & $8(12.1)$ & $58(87.9)$ & 1 \\
\hline $25-34$ & $46(19.6)$ & $189(80.4)$ & $1.76(0.78,3.95)$ \\
\hline $35-44$ & $33(24.1)$ & $104(75.9)$ & $2.30(0.99,5.31)$ \\
\hline$\geq 45$ & $19(32.8)$ & $39(67.2)$ & $3.53(1.41,8.87)$ \\
\hline \multicolumn{4}{|l|}{ Sex } \\
\hline Male & $55(26.4)$ & $153(73.6)$ & $0.59(0.39,0.92)$ \\
\hline Female & $51(17.7)$ & 237 (82.3) & 1 \\
\hline \multicolumn{4}{|l|}{ Marital status } \\
\hline Divorced & 14 (25.9) & $40(74.1)$ & $1.25(0.44,3.52)$ \\
\hline Married & 69 (21.5) & $252(78.5)$ & $0.98(0.40,2.36)$ \\
\hline Single & $13(21.7)$ & 47 (78.3) & $0.41(0.09,1.77)$ \\
\hline Separated & $3(10.3$ & 26 (89.7) & $0.99(0.35,2.79)$ \\
\hline Widowed & 7 (21.9) & $25(78.1)$ & 1 \\
\hline \multicolumn{4}{|l|}{ Religion } \\
\hline Muslim & $6(28.6)$ & $15(71.4)$ & 1 \\
\hline Orthodox & $69(20.7)$ & 265 (79.3) & $0.65(0.24,1.74)$ \\
\hline Protestant & $31(22.0)$ & $110(78.0)$ & $0.70(0.25,1.97)$ \\
\hline \multicolumn{4}{|l|}{ Level of educational } \\
\hline No education & $29(25.0)$ & $87(75.0)$ & $1.03(0.48,2.18)$ \\
\hline Primary & $30(17.8)$ & $139(82.2)$ & $0.66(0.32,1.39)$ \\
\hline Secondary & $34(21.5)$ & $124(78.5)$ & $0.84(0.40,1.75)$ \\
\hline Tertiary & $13(24.5)$ & $40(75.5)$ & 1 \\
\hline \multicolumn{4}{|l|}{ Occupation } \\
\hline Farmer & $5(20.8)$ & $19(79.2)$ & 1 \\
\hline Government employ & $21(29.2)$ & $51(70.8)$ & $1.56(0.52,4.74)$ \\
\hline Housewife & $30(19.0)$ & $128(81.0)$ & $0.89(0.31,2.57)$ \\
\hline Merchant & $8(18.2)$ & $36(81.8)$ & $0.84(0.24,2.94)$ \\
\hline Private gainful work & $15(22.4)$ & $52(77.6)$ & $0.98(0.34,2.88)$ \\
\hline Others (unspecified Job) & $27(20.6)$ & $104(79.4)$ & $1.09(0.35,3.43)$ \\
\hline \multicolumn{4}{|l|}{ Addiction } \\
\hline Addicted & $15(38.5)$ & $24(61.5)$ & $2.51(1.27,4.98)$ \\
\hline Not addicted & 91 (19.9) & $366(80.1)$ & 1 \\
\hline \multicolumn{4}{|l|}{ Family size } \\
\hline$\leq 2$ & $19(15.0)$ & $108(85.0)$ & 1 \\
\hline $3-4$ & $55(24.9)$ & $166(75.1)$ & $1.88(1.06,3.35)$ \\
\hline$\geq 5$ & $32(21.6)$ & $116(78.4)$ & $1.57(0.84,2.93)$ \\
\hline \multicolumn{4}{|l|}{ Cigarette smoking status } \\
\hline Yes & $20(46.5)$ & $23(53.3)$ & $3.71(1.95,7.06)$ \\
\hline No & $86(19.0)$ & 367 (81.0) & 1 \\
\hline \multicolumn{4}{|l|}{ Disclosure status } \\
\hline Disclosed & $106(21.5)$ & 386 (78.5) & 1 \\
\hline Not disclosed & $0(0.0)$ & $4(100)$ & $2.51(1.27-4.98)$ \\
\hline
\end{tabular}


stage and hemoglobin level were important risk factors for incidence of TB among HIV infected patients.

Thus, an individual who live in the family size of 3 - 4 was two times (AOR: 2.26, 95\% CI (1.14 - 4.50)) at risk of developing Tuberculosis among HIV than an individual who live in the family of less than or equal to two.

WHO clinical staging is Predictor for incidence of Tuberculosis among HIV patients; accordingly HIV patients with clinical stage III 20 times (AOR: 20.26, 95\% CI (7.09 - 57.6)) and stage IV 22 times (AOR: 22.9, 95\% CI (6.91 - 76.4)) were more likely to develop tuberculosis than an individual who were enrolled to ART clinic on the first WHO clinical stage.

Other factor that affect TB incidence among PLHIV was level of hemoglobin. According to this study an individual with hemoglobin level of less than $10 \mathrm{mg} / \mathrm{dl}$ was 2.5 times ((AOR: 2.56, 95\% CI (1.22 - 5.33)) highly acquire TB than an individual with hemoglobin level of greater than ten (see Table 5)

Other socio demographic and clinical characteristics like; Age in group ( $\geq 45)$, addiction (Addicted), sex of respondent, CD4 count, ART intervention(HAART), type of initial regimen and history of past TB treatment

Table 5. Predictors of incidence of tuberculosis among PLHIV patients in Arba Minch General Hospital, 2015.

\begin{tabular}{|c|c|c|c|c|c|}
\hline \multirow{2}{*}{ Variables } & \multicolumn{2}{|c|}{ Incidence of TBC } & \multirow{2}{*}{ COR $(95 \%$ CI) } & \multirow{2}{*}{ AOR (95\% CI) } & \multirow{2}{*}{ P-Value } \\
\hline & Yes & No & & & \\
\hline \multicolumn{6}{|l|}{ Age } \\
\hline $15-24$ & $8(12.1)$ & $58(87.9)$ & 1 & \multirow{4}{*}{ - } & \\
\hline $25-34$ & $46(19.6)$ & $189(80.4)$ & $1.76(0.78,3.95)$ & & \\
\hline $35-44$ & $33(24.1)$ & $104(75.9)$ & $2.30(0.99,5.31)$ & & \\
\hline$\geq 45$ & $19(32.8)$ & $39(67.2)$ & $3.53(1.41,8.87$ & & \\
\hline \multicolumn{6}{|c|}{ Disclosure status } \\
\hline Disclosed & $106(21.5)$ & $386(78.5)$ & $2.51(1.27-4.98)$ & - & \\
\hline Not disclosed & $0(0.0)$ & $4(100)$ & 1 & & \\
\hline \multicolumn{6}{|l|}{ Family size } \\
\hline$\leq 2$ & $19(15.0)$ & $108(85.0)$ & 1 & 1 & \\
\hline $3-4$ & 55 (24.9) & 166 (75.1) & $1.88(1.06,3.35)$ & $2.26(1.14-4.50)$ & 0.02 \\
\hline$\geq 5$ & $32(21.6)$ & $116(78.4)$ & $1.57(0.84,2.93)$ & $1.76(0.83-3.69)$ & 0.14 \\
\hline \multicolumn{6}{|c|}{ Cigarette smoking } \\
\hline Yes & $20(46.5)$ & $23(53.6)$ & $3.71(1.95,7.06)$ & $2.82(1.27-6.27)$ & \\
\hline No & $86(19.0)$ & $367(81.0)$ & 1 & 1 & 0.011 \\
\hline \multicolumn{6}{|c|}{ ART intervention } \\
\hline Pre-ART & 16 (11.7) & $121(88.3)$ & 1 & - & \\
\hline HAART & $90(25.1)$ & $269(74.9)$ & $2.53(1.43,4.49)$ & & \\
\hline \multicolumn{6}{|c|}{ Type of initial regimen } \\
\hline $1 \mathrm{a}$ & 19 (11.7) & $121(88.3)$ & $1.32(0.68,2.55)$ & & \\
\hline $1 \mathrm{~b}$ & 19 (29.7) & $45(70.3)$ & $2.82(1.36,5.85)$ & & \\
\hline 1c & $5(8.3)$ & $21(52.5)$ & $0.28(0.11,0.76)$ & - & \\
\hline $1 \mathrm{~d}$ & $13(23.6)$ & $55(91.7)$ & $0.96(0.46,2.00)$ & & \\
\hline $1 e+1 f$ & $34(24.3)$ & $42(76.4)$ & 1 & & \\
\hline \multicolumn{6}{|c|}{ Past TB treatment history } \\
\hline Yes & $22(32.4)$ & $46(67.6)$ & $1.96(1.12,3.43)$ & - & \\
\hline No & $84(19.6)$ & $344(80.4)$ & 1 & & \\
\hline \multicolumn{6}{|c|}{ WHO clinical stage } \\
\hline I & $7(6.1)$ & 108 (93.9) & 1 & 1 & \\
\hline II & $6(3.5)$ & $164(96.5)$ & $0.56(0.18,1.72)$ & $0.33(0.06-1.86)$ & 0.21 \\
\hline III & $76(43.9)$ & $97(56.1)$ & $12.0(5.31,27.5)$ & $20.26(7.09-57.6)$ & $<0.001$ \\
\hline IV & $17(44.7)$ & $21(55.3)$ & $12.5(4.61,33.8)$ & $22.9(6.91-76.4)$ & $<0.001$ \\
\hline \multicolumn{6}{|l|}{ CD4 count } \\
\hline$<50$ & $20(57.1)$ & 15 (42.5) & $13.4(6.10,29.4)$ & & \\
\hline $50-100$ & $23(39.7)$ & 35 (60.3) & $6.59(3.38,12.8)$ & & \\
\hline $101-200$ & 38 (29.9) & $89(70.1)$ & $4.28(2.44,7.50)$ & & \\
\hline 200 & $25(9.1)$ & 251 (90.9) & 1 & & \\
\hline \multicolumn{6}{|l|}{ Hemoglobin } \\
\hline$<10$ & & & 1 & 1 & \\
\hline$\geq 10$ & 24 (48) 82 (18.4) & 26 (52) 364 (81.6) & $3.46(1.30,9.18)$ & $2.56(1.22-5.33)$ & 0.012 \\
\hline
\end{tabular}

Note: significant $\leq 0.05$. 
(treated) were significant predictors of tuberculosis among HIV infected patients in bivariable analysis, but the association was diluted in multivariable analysis.

\section{Discussion}

Since the introduction of HIV infection in the world, TB is one of common opportunistic infection and Persons co-infected with TB and HIV were 21 - 34 times more likely to develop active TB disease than persons without HIV [20].

In this study, cumulative incidence and overall incidence rate of TB were $21.4 \%$ and 5.36 per 100 PY respectively.

This study used cumulative incidence of TB as outcome variable. Thus, cumulative incidence of Tuberculosis (21.4\%) reported in this study was lower than study done in former capital of Tanzania, Dares Salaam (27.1\%) and study done in North west Ethiopia (Debre Markos hospital) (44\%) [21]. But, the finding was higher than studies done in Spain and Brazil which were 7.7\% [22], and 4.62\% [23] respectively. Higher incidence rate could be explained by the fact that unlike these two countries, Ethiopia is one of the high TB burden countries in the world [24] besides advanced economic development compared to Ethiopia might improve HIV chronic care and reduce occurrence of TB. Lower cumulative incidence might due to improved TB/HIV chronic care and introduction of new regimen which effectively prevent occurrence of TB among HIV. Overall cumulative density reported in this study was lower than studies done in many other Sub Sahara African countries including, Ethiopia with reported incidence rate ranging from 5.4 to 11 per $100 \mathrm{PY}$ [25]-[28]. Lower incidence rate could be explained by improved TB/HIV Care and new introduction of regimen which effectively prevent occurrence of TB among HIV.

In multivariable analysis; Family size, History of Cigarettes smoking, WHO Baseline clinical stage and hemoglobin level were important predictors of incidence of Tuberculosis among HIV infected patients.

This study could establish association between TB and number of people in the household. Thus, an individual who live in the family size of 3 - 4 was two times at risk of developing Tuberculosis than an individual who live in family with $<2$ children. It is consistent with Studies, which have shown that risk of TB was associated with the number of people living together in the household (overcrowding) [29]-[31], but inconsistent with study done in Addis Ababa [32]. This might be related to high proportions of married persons in the study population resulted in high number of family size in the house hold which might resulted overcrowding which exposed HIV infected patients to Tuberculosis.

Others predictors associated with incidence of tuberculosis was history of cigarette smoking, thus cigarette smoker were 3 times at higher risk of developing TB than non-smokers. The finding was consistent with study done in Taiwan [33] and not consistent with study done in northwest Ethiopia and Burkina that cigarette smoking had no effect on occurrence of TB among HIV infected patients [13] [31]. This might due to person who smoke cigarette was exposed for low immunity and this would increase the risk of developing Tuberculosis among HIV infected patients. Furthermore cigarette smoking was associated with other substance abuse which can increase the risk of unprotected sexual intercourse and compromisation of immunity, resulting in occurrence of TB.

Baseline WHO clinical staging was strong predictor for Incidence of Tuberculosis; accordingly HIV patients with clinical stage III and IV were 20 and 22 times more likely develop tuberculosis than an individual who was started follow up on the first WHO clinical stage. The finding was supported by different study done in Ethiopia [12] [13] [32] [34], the similarity might be due to starting ART in advanced stage will reduce immunity and expose an individual for TB. It also suggests that HIV patients who had WHO stage III or IV might be immunecompromised and predisposed to TB.

In addition, patients having a hemoglobin level of $<10 \mathrm{mg} / \mathrm{dl}$ have 2.5 times higher risk of developing TB than those patients having hemoglobin level $10.0 \mathrm{mg} / \mathrm{dl}$, the finding was similar to other study findings in south west Ethiopia [34] and case control study done in Addis Ababa [32]. This shows that patients having higher hemoglobin level were less likely to develop TB than those with low level of hemoglobin. TB and hemoglobin level might be indirectly associated with advanced stage of HIV disease. When HIV positive patients have chronic disease and high viral load, it resulted in immune-suppression and suppression of red blood production in bone marrow. This is also consistent with the previous findings that predict the occurrence of TB which implied that advance disease condition in HIV patients may predict occurrence of Tuberculosis after ART initia- 
tion.

Other factors like; Age in group, addiction, sex of respondent, CD4 count, ART intervention, type of initial regimen and past history of TB treatment were significant predictors of incidence of tuberculosis among HIV infected patients in bivariable analysis, but the effect of this socio demographic and clinical characteristics were diluted in multivariable analysis.

Analysis of the past history of TB after adjustment, that it was a TB risk factor among PLWHAs, which is in agreement with a number of previous studies [15] [29] [34], But this was not the case in the study done in Arba Minch Hospital (our study), which reported that the past history of TB was not independent predictor of incidence of TB.

Many studies have used the patients' CD4 cell counts to assess association between CD4 Count and TB incidence and found that a lower CD4 cell count was associated with a higher risk of TB infection [13] [31] [35]. These studies are not consistent with our findings where the median CD4 cell count was not significant predictors of TB among HIV infected patients, though it had significant effect on occurrence of Tuberculosis in bivariable analysis.

The main limitation of our study was the retrospective nature of the cohort. The study individuals whose charts were lost not included in the study, which could undermine the result if the charts excluded were related to incidence of TB.

\section{Conclusion and Recommendation}

Cumulative and overall incidence rate of tuberculosis were found to be $21.4 \%$ and 5.36 per 100 PY respectively, which one was the highest. Family size, history of cigarettes smoking, heamoglobin level and WHO baseline clinical stage were important predictors of incidence of tuberculosis among HIV infected patients.

Finding that smoking is important predictors for TB in Ethiopia has obvious TB control implication which requires high attention focused on fighting against cigarette smoking in HIV infected populations.

The health institutions particularly work on lifestyle modification specifically on halting cigarette smoking habit through counseling. Early initiation of HAART as current guideline should get emphasis and behavioral education that discourages addiction is important to reduce the risk of TB infection. Furthermore, concomitant infections and risk factors for anemia among HIV patients should get managed and prevented.

\section{Acknowledgements}

The authors are very grateful to Arba Minch General Hospital, for its administrative and technical assistance. Data collectors, supervisors and Arba Minch University deserves especial acknowledgement for data abstraction, care full supervision and provide ethical clearance to conduct this research work respectively.

\section{Competing Interest}

The authors declare that there is no competing interest

\section{Authors' Contributions}

${ }^{1}$ MD was the primary researcher, conceived the study, designed, participated in data collection and quality assurances, conducted data analysis, drafted and finalized the manuscript for publication. ${ }^{2} \mathbf{A T}$ was assisted in data collection and analysis and reviewed the initial and final drafts of the manuscript

\section{References}

[1] WHO (2014) Global Tuberculosis Report. WHO, Geneva, Switzerland.

[2] World Health Organization (2013) Global Tuberculosis Report.

[3] Corbett, E.L., et al. (2006) Tuberculosis in Sub-Saharan Africa: Opportunities, Challenges, and Change in the Era of Antiretroviral Treatment. The Lancet, 367, 926-937. http://dx.doi.org/10.1016/S0140-6736(06)68383-9

[4] World Health Organization (WHO) (2014) WHO Global TB Report, Ethiopian Tuberculosis Profile. WHO, Addis Abeba, Ethiopia.

[5] Getahun, H., et al. (2010) HIV Infection-Associated Tuberculosis: The Epidemiology and the Response. Clinical In- 
fectious Diseases, 50, 201-207. http://dx.doi.org/10.1086/651492

[6] Deribew, A., Tesfaye, M., Hailmichael, Y., Negussu, N., Daba, S., Wogi, A., Belachew, T., Apers, L. and Colebunders, R. (2009) Tuberculosis and HIV Co-Infection: Its Impact on Quality of Life. Health and Quality of Life Outcomes, 7, 105.

[7] Deribew, A., Tesfaye, M., Hailmichael, Y., Apers, L., Abebe, G., Duchateau, L. and Colebunders, R. (2010) Common Mental Disorders in TB/HIV Co-Infected Patients in Ethiopia. BMC Infectious Diseases, 10, 201. http://dx.doi.org/10.1186/1471-2334-10-201

[8] Burman, W., Weis, S. and Vernon, A. (2007) Frequency, Severity and Duration of Immune Reconstitution Events in HIV-Related Tuberculosis. The International Journal of Tuberculosis and Lung Disease, 11, 1282-1289.

[9] Lorent, N., Sebatunzi, O., Mukeshimana, G., Ende, J.V. and Clerinx, J. (2011) Incidence and Risk Factors of Serious Adverse Events During Antituberculous Treatment in Rwanda: A Prospective Cohort Study. Journal of Acquired Immune Deficiency Syndromes, 58, 32-37. http://dx.doi.org/10.1371/journal.pone.0019566

[10] Breen, R., Smith, C. and Bettinson, H. (2004) Paradoxical Reactions during Tuberculosis Treatment in Patients with and without HIV Co-Infection. Thorax, 59, 704-707. http://dx.doi.org/10.1136/thx.2003.019224

[11] Havlir, D., Kendall, M., Ive, P., Kumwenda, J., Swindells, S. and Qasba, S. (2011) Timing of Antiretroviral Therapy for HIV-1 Infection and Tuberculosis. The New England Journal of Medicine, 365, 482-491. http://dx.doi.org/10.1056/NEJMoa1013607

[12] Melkamu, H., Seyoum, B. and Dessie, Y. (2013) Determinants of Tuberculosis Infection among Adult HIV Positives Attending Clinical Care in Western Ethiopia: A Case-Control Study. AIDS Research and Treatment, 2013, Article ID: 279876. http://dx.doi.org/10.1155/2013/279876

[13] Alene, K.A., Nega, A. and Taye, B.W. (2013) Incidence and Predictors of Tuberculosis among Adult People Living with Human Immunodeficiency Virus at the University of Gondar Referral Hospital, Northwest Ethiopia. BMC Infectious Diseases, 13, No. 292.

[14] Sterling, T.R., et al. (2011) Risk Factors for Tuberculosis after Highly Active Antiretroviral Therapy Initiation in the United States and Canada: Implications for Tuberculosis Screening. The Journal of Infectious Diseases, 204, 893-901. http://dx.doi.org/10.1093/infdis/jir421

[15] Seyler C, et al. (2005) Risk Factors for Active Tuberculosis after Antiretroviral Treatment Initiation in Abidjan. American Journal of Respiratory and Critical Care Medicine, 172, 123-127. http://dx.doi.org/10.1164/rccm.200410-13420C

[16] USAIDS (2012) TB Care I, Tuberculosis Report of Ethiopia. TB Care, Addis Abeba.

[17] Jerene, D., Næss, A. and Lindtjørn, B. (2006) Antiretroviral Therapy at a District Hospital in Ethiopia Prevents Death and Tuberculosis in a Cohort of HIV Patients. AIDS Research and Therapy, 3, 10.

[18] Alemie, G.A. and Gebreselassi, F. (2014) Common Types of Tuberculosis and Co-Infection with HIV at Private Health Institutions in Ethiopia. BMC Public Health, 14, 319.

[19] Belay, A., Alamrew, Z., Berie, Y., Tegegne, B., Tiruneh, G. and Feleke, A. (2013) Magnitude and Correlates of Tuberculosis among HIV Patients at Felege Hiwot Referral Hospital, Bahir Dar City, Northwest Ethiopia. Clinical Medicine Research, 2, 77-83. http://dx.doi.org/10.11648/j.cmr.20130204.18

[20] WHO. TB/HIV Facts 2012-2013. http://www.who.int/hiv/topics/tb/tbhiv_facts_2013/en/

[21] Esmael, A., Tsegaye, G., Wubie, M. and Endris, M. (2013) Tuberculosis and Human Immune Deficiency Virus Co-Infection in Debre Markos Referral Hospital in Northwest Ethiopia: A Five Years Retrospective Study. Journal of AIDS \& Clinical Research, 4, 263. http://dx.doi.org/10.4172/2155-6113.1000263

[22] Muga, R., et al. (2007) Changes in the Incidence of Tuberculosis in a Cohort of HIV-Seroconverters before and after the Introduction of HAART. Aids, 21, 2521-2527. http://dx.doi.org/10.1097/QAD.0b013e3282f1c933

[23] De Lannoy, L.H., Cortez-Escalante, J.J., Evangelista, M.D.S.N. and Romero, G.A.S. (2008) Tuberculosis Incidence and Risk Factors among Patients Living with HIV/AIDS in Public Health Service Institutions in Brasilia, Federal District. Revista da Sociedade Brasileira de Medicina Tropical, 41, 549-555. http://dx.doi.org/10.1590/S0037-86822008000600001

[24] Reid, A., et al. (2006) Towards Universal Access to HIV Prevention, Treatment, Care, and Support: The Role of Tuberculosis/HIV Collaboration. The Lancet Infectious Diseases, 6, 483-495. http://dx.doi.org/10.1016/S1473-3099(06)70549-7

[25] Ngowi, B.J., Mfinanga, S.G., Bruun, J.N. and Morkve, O. (2008) Pulmonary Tuberculosis among People Living with HIV/AIDS Attending Care and Treatment in Rural Northern Tanzania. BMC Public Health, 8, 341. http://dx.doi.org/10.1186/1471-2458-8-341

[26] Iliyasu, Z. and Babashani, M. (2008) Prevalence and Predictors of Tuberculosis Co-Infection among HIV-Seropositive 
Patients Attending the Aminu Kano Teaching Hospital, Northern Nigeria. Journal of Epidemiology, 19, 81-87. http://dx.doi.org/10.2188/jea.JE20080026

[27] Assefa, D., Melaku, Z., Gadissa, T., Negash, A., Hinderaker, S.G. and Harries, A.D. (2011) Intensified Tuberculosis Case Finding among People Living with the Human Immunodeficiency Virus in a Hospital Clinic in Ethiopia [Notes from the Field]. The International Journal of Tuberculosis and Lung Disease, 15, 411-413.

[28] Alene, K.A., Nega, A. and Taye, B.W. (2013) Incidence and Predictors of Tuberculosis among Adult People Living with Human Immunodeficiency Virus at the University of Gondar Referral Hospital, Northwest Ethiopia. BMC Infectious Diseases, 13, 292. http://dx.doi.org/10.1186/1471-2334-13-292

[29] Hill, P.C., Jackson-Sillah, D., Donkor, S.A., Otu, J., Adegbola, R.A. and Lienhardt, C. (2006) Risk Factors for Pulmonary Tuberculosis: A Clinic-Based Case Control Study in the Gambia. BMC Public Health, 6, 156. http://dx.doi.org/10.1186/1471-2458-6-156

[30] Hermans, S.M., Kiragga, A.N., Schaefer, P., Kambugu, A., Hoepelman, A.I.M. and Manabe, Y.C. (2010) Incident Tuberculosis during Antiretroviral Therapy Contributes to Suboptimal Immune Reconstitution in a Large Urban HIV Clinic in Sub-Saharan Africa. PLoS ONE, 5, e10527. http://dx.doi.org/10.1371/journal.pone.0010527

[31] Meda, Z.C., et al. (2013) Risk Factors of Tuberculosis Infection among HIV/AIDS Patients in Burkina Faso. AIDS Research and Human Retroviruses, 29, 1045-1055. http://dx.doi.org/10.1089/aid.2012.0239

[32] Kibret, K.T., Yalew, A.W., Belaineh, B.G. and Asres, M.M. (2013) Determinant Factors Associated with Occurrence of Tuberculosis among Adult People Living with HIV after Antiretroviral Treatment Initiation in Addis Ababa, Ethiopia: A Case Control Study. PLoS ONE, 8, e64488. http://dx.doi.org/10.1371/journal.pone.0064488

[33] Ariyothai, N., Podhipak, A., Akarasewi, P., Tornee, S., Smithtikarn, S. and Thongprathum, P. (2004) Cigarette Smoking and Its Relation to Pulmonary Tuberculosis in Adults. The Southeast Asian Journal of Tropical Medicine and Public Health, 35, 219-227.

[34] Taha, M., Deribew, A., Tessema, F., Assegid, S., Duchateau, L. and Colebunders, R. (2011) Risk Factors of Active Tuberculosis in People Living with HIV/AIDS in Southwest Ethiopia: A Case Control Study. Ethiopian Journal of Health Sciences, 21, 131-140.

[35] Kruk, A., et al. (2011) Tuberculosis among HIV-Positive Patients across Europe: Changes over Time and Risk Factors. Aids, 25, 1505-1513. http://dx.doi.org/10.1097/QAD.0b013e328348fafd

\section{Abbreviations and Acronyms}

AGH: Arba Minch General Hospital; AIDS: Acquired Immuno Deficiency Syndrome; ART: Active Antiretroviral Therapy; AZT: Zidovudine; EFV: Efavirenz; HAART: Highly Active Antiretroviral Therapy; IRIS: Immune Reconstitution Inflammatory Syndrome; NVP: Nevirapine; OIs: Opportunistic Infections; PY: Person Years; SPSS: Statistical Package for Social Science; TB: Tuberculosis; 3TC: Lamuvudine; WHO: World Health Organization. 